\title{
"Wisdom of the Elders" or "Loss of Experience" as a Mechanism to Explain the Decline in Traditional Ecological Knowledge: A Case Study on Awaji Island, Japan
}

\author{
Kaori Okui ${ }^{1,2} \cdot$ Yoshihiro Sawada ${ }^{3,4} \cdot$ Takehito Yoshida $^{5,6}$
}

Accepted: 5 January 2021 / Published online: 2 July 2021

(c) The Author(s) 2021

\begin{abstract}
Previous studies have reported that older people are more knowledgeable about nature than the younger generation. The relationship between people's age and level of knowledge can be explained via two mechanisms: knowledge increases with age (wisdom of the elders), and opportunities to acquire knowledge decrease with successive generations (loss of experience). In this study, we examined the association between age and knowledge regarding the use of wild fruits among people living on Awaji Island in Japan. Analysis of the results revealed that the decline in knowledge among young people can be attributed to loss of experience. Furthermore, we found that the channels of knowledge transfer have changed between generations, earlier, children received it from their peers, but in recent years, it has been coming to them from older people and teachers.
\end{abstract}

Keywords Age effect $\cdot$ Cohort effect $\cdot$ Traditional ecological knowledge $\cdot$ Loss of local ecological knowledge $\cdot$ Cultural transmission of local knowledge $\cdot$ Wild fruits $\cdot$ Awaji Island, Hyogo, Japan

\section{Introduction}

Local ecological knowledge (LEK) refers to human's ability to use their natural surroundings, and especially the knowledge that has been passed down through generations, is called traditional ecological knowledge (TEK). LEK and TEK have been actively studied across the globe since the 1980s (Berkes et al. 2000). TEK can be wide-ranging, including the knowledge and skills used in the conservation of rare species (Uchida and Kamura 2020), management of protected areas (Gómez-Baggethun et al. 2010), and the use of sustainable resources (Berkes 1999). Many earlier studies

Kaori Okui

kinomiquest@gmail.com

1 Museum of Nature and Human Activities, Hyogo, Hyogo, Japan

2 ECO-PLANNING RESEARCH Co. Ltd., Tokyo, Japan

3 University of Hyogo, Hyogo, Japan

4 Awaji Landscape Planning and Horticulture Academy, Hyogo, Japan

5 Research Institute for Humanity and Nature, Kyoto, Japan

6 University of Tokyo, Tokyo, Japan focused on the knowledge of indigenous peoples, also known as Indigenous Ecological Knowledge; in contrast, knowledge regarding the use of natural resources in developed countries has gained attention in recent years. Gómez-Baggethun et al. (2010) studied changes in traditional knowledge in agriculture and livestock farming among three generations in communities linked to protected areas in Doñana, southwestern Spain, revealing a decline in knowledge between generations. Von Glasenapp and Thornton (2011) assessed the status and pragmatics of TEK in relation to the evolving sociopolitical and climate changes in the Swiss Alpine community of Vals, and discussed how it can contribute to resilience and adaptability vis-à-vis those changes affecting the community. Olsson and Folke (2001) explored the role of LEK through a local fishing association in a contemporary rural Swedish community, and clarified how such knowledge and practice are embedded in and influenced by institutions across scales. Thus, the local and traditional knowledge of using nature is not only for indigenous peoples, but is also relevant for ecosystem management and conservation in other regions, including any developed countries.

All of the previous studies that reviewed TEK/LEK found the decline in or loss or degradation of knowledge over recent years to be the dominant trend. For example, Hanazaki et al. (2013) reported that $57 \%$ of the 84 studies 
on traditional uses of plants indicated a decline in or loss of knowledge, Aswani et al. (2018) found a similar trend for $77 \%$ of the 92 studies on LEK, and Tang and Gavin (2016) reported that TEK degradation was by far the most common trend noted (89\% of 152 studies; $87 \%$ of 137 questionnaire respondents). Although there were some cases that the trend of decreasing knowledge was not observed (Zarger and Stepp 2004), overall, the knowledge about uses of natural resources has been lost in many parts of the world. Furthermore, many studies have shown a correlation between age and knowledge, suggesting that older people are more knowledgeable than younger people (e.g., Sujarwo et al. 2014; Ianni et al. 2015).

There are two possible mechanisms to explain the correlation between age and knowledge (Godoy et al. 2009; Reyes-García et al. 2013; Koster et al. 2016): (a) Wisdom of the elders: knowledge accumulates with age. This is also called the "age effect;" and (b) Loss of experience: opportunities to acquire knowledge decrease with each successive generation. This is also referred to as the "cohort effect."

If the age effect is predominant over the cohort effect, there exists possibility where knowledge increases with age, and young generations should acquire it in the future. If the cohort effect is more important than the age effect, it suggests that knowledge is actually declining over generations. Only a few studies have attempted to evaluate the role of these mechanisms, although the importance of this evaluation has been emphasized (Godoy et al. 2009; Reyes-García et al. 2013). Gómez-Baggethun, et al. (2010), in their study of the Doñana Natural Areas in Spain, did in fact confirm the importance of age effect. In contrast to these earlier studies that used regression analysis to examine the mechanisms, our study devised a new method to examine the age at which transmission occurred to understand the mechanism of knowledge decline.

Loss of knowledge is associated with loss of knowledge transmission. Tang and Gavin (2016) classified "loss of pathways of TEK transmission" as the first category of direct threats to TEK. Cavalli-Sforza and Feldman (1981) introduced three models of cultural transmission: "vertical" transmission, in which knowledge is passed down from parents to children; "horizontal" transmission, in which knowledge transmission occurs between peers; and "oblique" transmission, in which knowledge is passed on from the older generation to the younger one without family relationship, as well as from teachers and mass media. How and when knowledge is transferred and from whom to whom depends on the domain of knowledge and the local context. For example, in a previous study on the use of wild edible plants in India, vertical transmission from mothers to children was important (Cruz-Garcia 2006). In contrast, fathers were the primary transmitters of TEK in an Inuit community in Canada (Pearce et al. 2011). In the Hutulus communities of Ukraine and Romania, books were an important medium of plants-related knowledge transfer on the Ukrainian side, whereas on the Romanian side, it was older people with a wealth of knowledge (Mattalia et al. 2020). The relationship between age and knowledge of natural resource uses depends on the time dedicated to such uses in daily life (Koster et al. 2016). In addition, it has been pointed out that different domains of knowledge follow different secular trends. For example, among the Tsimané in the Bolivian Amazon, while knowledge of house building has not declined, that of edible wild plants and medicines has been shown to be easy to lose (Reyes-García et al. 2013). These studies highlight the importance of knowledge transmission in understanding the loss of knowledge and proposing effective measures to conserve knowledge over generations.

The present study focused on the actual use of wild fruits, a typical use of natural resources, on Awaji Island, Hyogo Prefecture, Japan, and compared the experience of this use between generations. We used the method described in the next section to separate the age effect from the cohort effect and analyze whether knowledge of natural resource use is actually declining. Additionally, we aim to clarify the intergenerational changes in channels of knowledge transfer, and discuss how knowledge transfer can be sustained in the future.

\section{Materials and Methods}

\section{Study Site}

Awaji Island is located approximately $34^{\circ} \mathrm{N}$ and $134^{\circ} \mathrm{E}$, and has an area of $592.5 \mathrm{~km}^{2}$ (Fig. 1). Located in the southern part of Hyogo Prefecture, it comprises three cities and various types of settlements, including urban areas, rural villages in plains, and mountain and fishing villages. The island has abundant natural resources, with $51.6 \%$ of forest cover as of 2015 (Ministry of Agriculture, Forestry and Fisheries 2015), and it has not yet been seen largescale urbanization (Himiyama 1995). It has been reported that forest cover across Awaji Island decreased by approximately $0.5 \%$ between the early 1800 s and the 1980 s (Ichinose and Ito 2007). According to the Statistics Bureau of Japan (2015), the island has a population of approximately 135,000 , and $13.7 \%$ of the employed islanders aged over 15 are engaged in agriculture; when compared with the national average of $3 \%$, it is clear that agriculture is thriving on the island. In contrast, $3 \%$ of the islanders are involved in the fishing industry, which is roughly equal to the national average. Manufacturing accounts for $15 \%$ (national average $3.5 \%$ ), retail and wholesale trade $14 \%$ (national average $3.4 \%$ ), and health and welfare $12 \%$ (national average 7.4\%). Close to Osaka and Kobe, Japan's third most and seventh most populous cities, respectively, 
Fig. 1 Location of the study area, Awaji Island in Hyogo Prefecture, Japan

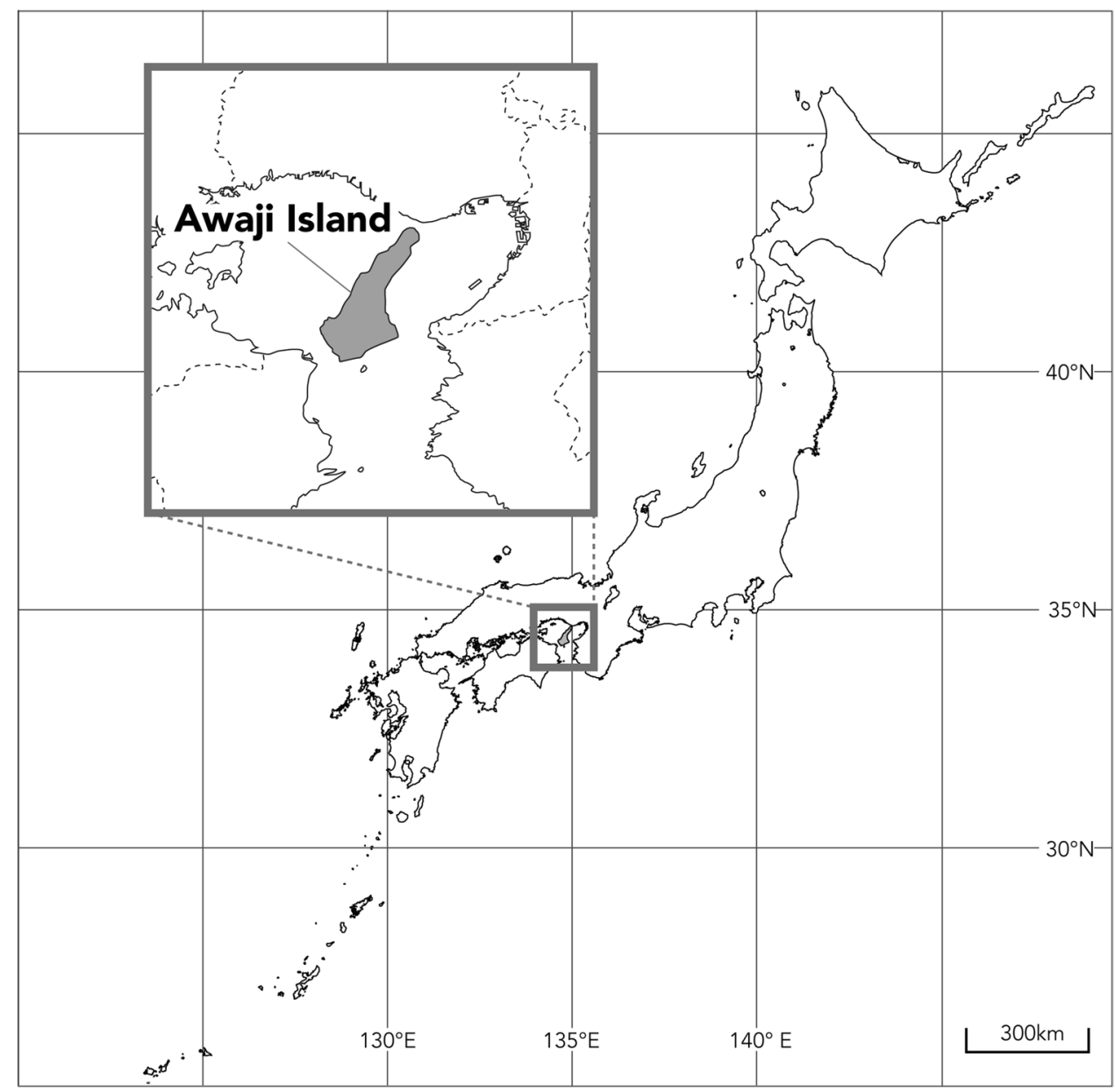

this island is visited by many day trip and overnight tourists. The islanders, like those in most of Japan except for big cities, have lived here for many generations.

The average annual temperature is 15.5 degrees Celsius, and the annual rainfall is about $1,400 \mathrm{~mm}$ (Japan Meteorological Agency 2020), indicating a temperate climate (Beck et al. 2018). The main forests on Awaji Island are those of evergreen broadleaf trees such as Castanopsis, deciduous broadleaf trees such as Quercus serrata, and Pinus densiflora trees (Biodiversity Center of Japan, Ministry of the Environment n.d.). Most of these forests are secondary ones. According to the "Flora of the Awaji Island (revised and enlarged edition)" compiled by Kobayashi et al. (2012), at least 1,524 species belonging to 173 families of vascular plants have been documented on the island ( $15.5 \%$ of them are naturalized or escaped species).

We conducted a qualitative interview survey (unstructured interviews) of 40 people born and raised on Awaji Island and a quantitative questionnaire survey of 228 people, in 2015 and 2016 (Tables S1, S2). The birthplaces of the informants in both surveys covered a wide area of the island.

\section{Unstructured Interviews}

Informants selection for the qualitative survey proceeded by requesting the first informant to nominate the next one to be interviewed. This allowed us to find someone with an abundant knowledge and encourage them to speak freely. However, not all informants were known to each other, and in order to interview a wide range of generations, we sometimes asked for referrals based solely on age criteria, such as their parents or children. In order to avoid any bias in the area of residence among the informants, that of the next informants was designated as necessary.

Each informant was interviewed for around one to two hours and, in most cases, one at a time; on rare occasions, two to four informants were interviewed at the same timethese interviews were conducted within three hours. Informants were encouraged to talk frankly about their experience of using and memories of wild fruits, while we used supplemental materials such as photographs, real wild fruits, and maps to elicit their memories. Based on the information obtained from the interviews, we listed species, usage, and the common names of wild fruits that had been used by 
the informants (Table S3). We interviewed informants of all ages, from those born in the 1920s to the 1990s, though approximately half of them were born between the 1930s and 1950s (Table S1).

\section{Questionnaire Survey}

We designed the quantitative survey based on the responses obtained in the qualitative one. The questionnaire included informants' birth year and gender as well as the places where they lived and the duration of stay. They were asked about their experience of using six species of wild fruits (Rubus spp., Elaeagnus spp., Akebia spp., Castanopsis spp., Morella rubra, and Vitis spp.), the duration of their usage (age), and the source of their information on the fruits. We selected six species from those frequently mentioned by informants in the interviews, and these are still commonly found near the inhabited areas on the island. We also listed several local names of each wild fruit identified in the interviews. In addition, a free text box was provided in the questionnaire to obtain information on the use of wild fruits of species other than these six.

Informants of qualitative survey and their family and friends participated in the questionnaire survey. We also asked groups such as the local fire brigade to take part and participated in local festivals where local people gathered in order to find more informants. We also asked teachers in a local junior high school to conduct questionnaire survey in their classes.

The relationship between knowledge about the use of wild fruits and age was analyzed by linear regression. Informants who had not answered any part of the questionnaire were excluded from the analysis. We also excluded informants aged 11 or below from the comparison of the 12 years, from age 0 to 12 , between generations, leaving 187 informants. To assess the mechanism explaining the decline in knowledge, we first evaluated when each informant put specific knowledge to use during their lifetime, and then compared the results for the same age between the generations. This allowed the evaluation of the "cohort effect" by subtracting the "age effect." Additionally, we compared which knowledge holder passed on the information and to whom among the different generations. This analysis provided another aspect to help explain how the changes in knowledge transmission occurred.

\section{Results}

\section{Usage of Wild Fruits}

Based on the responses to the open-ended questions in the interview and questionnaire surveys, we confirmed the use of 50 species of wild fruits (Table S3). These included only wild fruits and excluded planted fruit trees and cultivars as well as herb fruits. Among the multiple species of wild raspberries and grapes, we listed only those whose use was confirmed. For example, 17 species of wild raspberries have been identified on Awaji Island; while people sometimes refer to them by their specific local names, they are in general called "noichigo" (Rubus spp.). We did not list those whose species could not be identified, even though they had local names. In addition, although all 17 species are edible, the use of six of them was confirmed in our surveys. The most common use of wild fruits (32 species) was "to eat." Also, six species were collected and sold, and 17 were used for other purposes, which included those related to daily life and rituals such as "to make toy(s)," "to get tannin (preservation)," "to extract oil," and "to sacrifice."

\section{Knowledge of using Wild Fruits}

Based on the responses in the interview survey, we categorized knowledge related to the use of wild fruits was categorized as:

- Recognition of names (especially local names): most wild fruits are referred to by their local names (Table S3), and different parts of the island have different names for some wild fruits (e.g., Ebiko, Ebuko, Nobudo, and Yamabudo for Vitis ficifolia). In addition, some of the species have different names depending on their size or sex (e.g., Mizumomo (big fruit) and Ishimomo (small fruit) for Morella rubra, Itabi (female tree), and Inuitabi (male tree) for Ficus erecta).

- Method of use: users were aware of the methods of collecting and processing wild fruits, their inedible parts, and how to use them. They also knew the care to be taken during harvesting, such as the brittleness of the branches. In addition, they had knowledge of using special tools to collect wild fruits (e.g., holding the umbrella upside down and collecting the fruits by shaking the trees, soaking Castanopsis sieboldii in water and eating only the sunk ones, and threading multiple wild raspberries through a long stem of grass to carry around).

- Habitat: users were familiar with the environment in which the wild fruits grew, specifically, the places where they grew. Knowledge regarding the places where good wild fruits can be found has been shared among peers or kept confidential (e.g., a large fruit-bearing tree is located behind the shrine (Castanopsis spp.), and Rubus parvifolius crawls on stone walls).

- Phenology: users recognized the seasons and processes of fructification of wild fruits (e.g., Actinidia rufa bears fruit in winter, and Elaeagnus pungens does not taste good until it becomes sufficiently red). 
Not all of the above information was provided for all fruits mentioned in the interviews, and the type and amount of information varied depending on the fruit.

\section{Relationship between Birth Year and Experience of using Wild Fruits}

The number of species used during an informant's lifetime increased with increase in age, and conversely, decreased with decrease in age (Fig. 2a). Regarding the duration of the use of wild fruits, most informants reported using them in childhood (below the age of 12) (Fig. 3). Also, many of them reported using them only during childhood, although some continued their usage into adulthood; only a few started using them in adulthood. In addition, the relationship between age and the number of species used until the age of 12 showed that the younger generation had used fewer species (Fig. 2a), while the older generation had used a larger number (Fig. 2b).

\section{Knowledge Transmission}

We divided the informants into four generations, and aligned the channels of knowledge transfer most frequently seen in each generation in descending order (Fig. 4). Approximately $40 \%$ of those born in the period 1920-1949 learned how to use wild fruits from their friends and seniors, but the percentage declined with increase in age. In the 1970-1989 generation, grandmothers were the most frequently cited channel of knowledge transfer at 45\%; for the 1990-2009 generation at $33 \%$. Knowledge transfer between siblings was

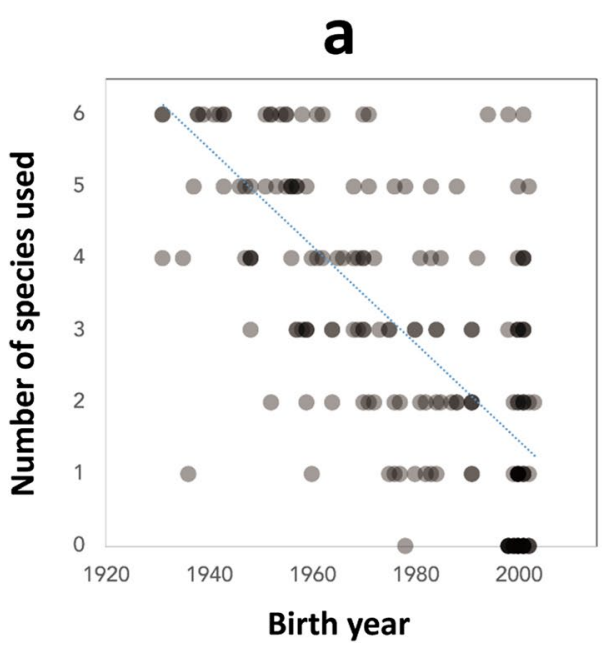

Fig. 2 a The relationship between an informant's birth year and his/ her experience (and underlying knowledge) of using wild fruits during his/her lifetime. The dotted line represents the result of the regression analysis; (number of species used during lifetime) $=$ $-0.0678 *$ (birth year) $+136.96, \mathrm{R}^{2}=0.4772, N=187$. b The rela- last seen in the 1970-1989 generation, and were not found in the subsequent generation. Meanwhile, teachers emerged as a new channel of knowledge transfer, more popular among the younger generations. In addition, it was found that for the older generations, knowledge was transferred by peers during childhood, but this channel has shifted to the elderly and adults for the younger generations. Moreover, traveling salespersons who were frequently cited as transmitters of knowledge in the 1920-1949 generation have disappeared in younger generations, and the young generations reported acquiring knowledge from the Internet, television, books, and other media.

\section{Discussion}

Our results revealed that the widely documented decline in TEK can be attributed to the decline in experience among younger generations, not the accumulation of knowledge with age (wisdom of the elders) (Figs. 2a, b and 3). We also found that the use of wild fruits began during childhood and rarely persists in adulthood. In addition, the channels of knowledge transfer were observed to have changed over generations. While those born between 1920 and 1949 acquired knowledge from their friends and seniors, the proportion of these channels has declined, and new channels emerged, in the younger generations. In this study, it was possible to compare the level of knowledge between the generations because the use of wild fruits started in childhood for all of them; had the start time differed between generations, this method would not have been able to compare them by

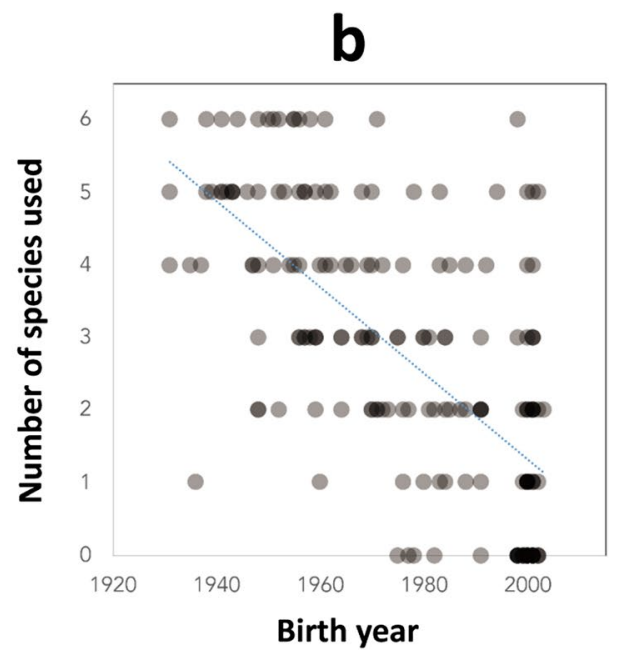

tionship between an informant's birth year and his/her experience of using wild fruits during his/her childhood (aged 12 or below). The dotted line represents the result of the regression analysis; (number of species used during childhood $)=-0.0596 *($ birth year $)+120.48, \mathrm{R}^{2}=$ $0.4549, N=187$ 

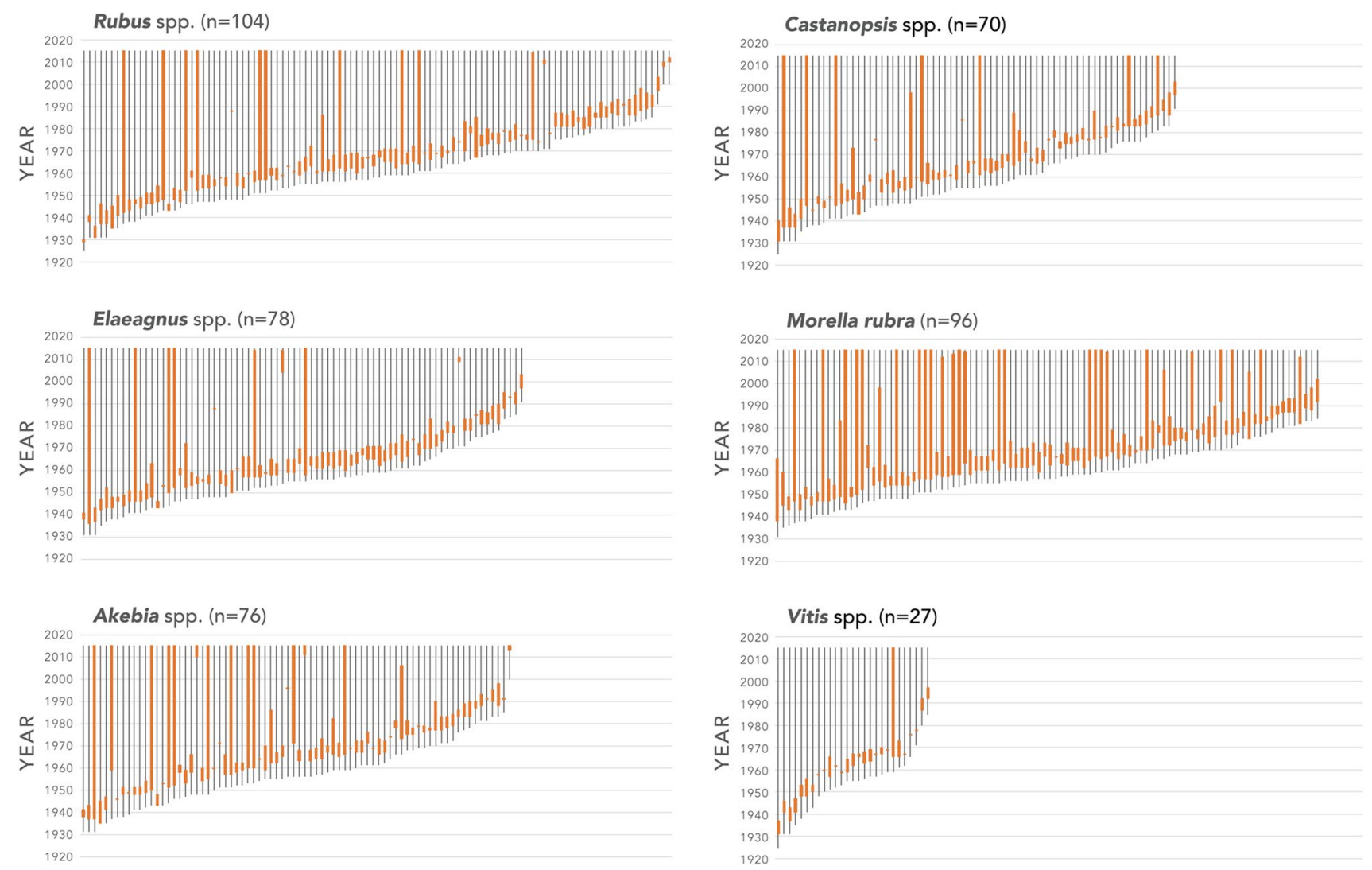

Fig. 3 Each informant's duration of wild fruit use. The thin line represents each informant's lifetime (birth year to 2015), whereas the thick one shows the duration of use within the lifetime. Data of only those informants who have used each wild fruit is shown here

Fig. 4 Channels of knowledge transfer (i.e., the source the informants acquired information about wild fruits from) for four different generations. The number indicates the percentage of use of each channel among the informants in each generation (each informant used more than one channel)

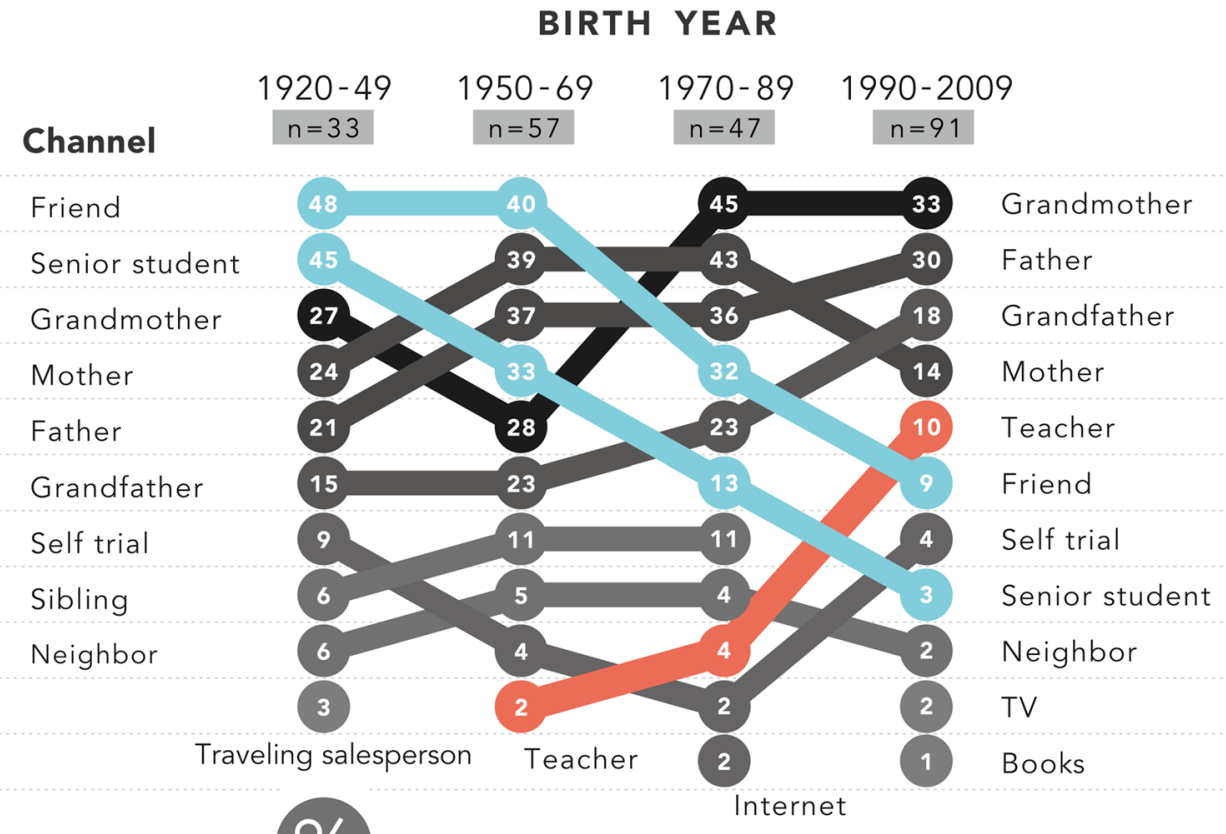


subtracting the age effect. To see if all generations used specific knowledge at the same age, it is important to understand the pattern of knowledge usage during people's lifetimes, as shown in Fig. 3.

\section{Acquisition of Knowledge in Life and Duration of its Use}

Previous studies have reported that the duration of using knowledge in one's lifetime varies depending on the area of the traditional knowledge (Reyes-García et al. 2013; Koster et al. 2016). In addition, it has been shown that people acquire considerable ecological knowledge about plants from their peers during childhood (Zarger and Stepp 2004). Our results show that the use of wild fruits as food not only begins but also tends to end in childhood, and a majority of those who continued to use wild fruits in adulthood began using them as children. It is imperative to understand the use of natural resources in order to promote conservation strategies that are appropriate and effective in maintaining knowledge transfer. For example, people in modern Japan are familiar with wild fruits during their childhood, but this interest tends to decline as they age. It is common in Japan to see young children playing with acorns in the fall, but it is rare to see students in junior high school, older students, or adults doing the same. Many informants said in the interviews that they often consumed wild fruits as snacks while playing and on their way home from school. Interest in wild fruits and opportunities to collect them diminish with age. By making use of the demands and opportunities corresponding to age, we can measure the transfer knowledge. Information about users and the duration of use of the knowledge is essential when considering sustaining knowledge transfer.

\section{Differences in Awareness of the Use of Wild Fruits Between Generations}

Since Awaji Island has not undergone rapid urbanization, wild fruits are still readily found around villages. Therefore, a decline in their use among younger generations is not likely due to changes in the natural environment. Despite there being enough wild fruits around, younger generations do not use them. The qualitative interview survey suggests that social context and changes in children's lifestyles are responsible for the decline in wild fruit use. Informants offer various accounts of the use of wild fruit. Some whose childhoods spanned the post-war food shortage era said, "I ate anything edible," a strategy never mentioned by other generations. This suggests that one of the uses of wild fruits"to eat"-became most important use of this resource in an era when food was scarce. War is an important factor when considering the use of wild fruits, and many of our informants gave war-related accounts of wild fruit uses in the surveys. However, those born between 1920 and 1940 who had reported consuming wild fruits in their childhood stated in 2015 that eating wild things was "barbaric," suggesting that personal values can change over time. CruzGarcía (2006) also found a similar situation in which the use of natural resources was seen as a symbol of low status and poverty, and associated with shame and inferiority.

Informants born in the 1970s noted that they had not played outdoors after the emergence of video games, which could also be one of the reasons that children become alienated from nature, suggesting a clear shift in the sources of children's play materials. Also, those born in the 1980s said that they rarely played outdoors on weekdays because they returned home late after participating in sports club or other activities at school. These statements demonstrate the impact of children's use of time on their use of wild fruits. Senda (1992) found that the amount of natural space available for children to play in declined by more than half between 1955 and 1990. Compared with Yokohama, the second-largest city in Japan with a sizeable population that was the site of Senda's study (1992), Awaji Island still has an abundance of nature, so it is unlikely that the amount of natural space for children has similarly decreased there. A previous study conducted on Awaji Island showed that children born in the late 1990s were less likely to play in nature than their parents (One et al. 2013). In addition, the number of children on Awaji Island has been declining, as one of the elementary schools shut down during the period of this study. Many children's schools are located far from their homes, and hence, they commute by bus or car. Possible reasons for the decrease in learning from friends and seniors include fewer children, lack of friends in the neighborhood, and a decrease in the amount of time children spend with each other during the commute between home and school.

\section{Changes in Channels of Knowledge Transfer}

Previous studies have shown that horizontal transmission is the most common channel of knowledge transfer for children (Gallois et al. 2018). However, our study showed that horizontal transmission in childhood has changed to vertical and oblique transmissions with time. Channels of knowledge transfer have shifted in recent years, highlighting not only changes in the relationship between people and nature but also the communication between people. Knowledge transfer between children, as experienced by the older generations, has been replaced by transfer from older people, such as grandmothers, for younger generations. In addition to the changes in the way children play and the places they frequent, this may demonstrate the changes in the relationship between children of the same or different ages. 
Teachers and to a lesser degree, television, books, and internet which were increasingly channels of transfer or emerging as such in the younger generations, are likely to bring knowledge that is outside of children's area of activity and not local. Due to this change in channels of knowledge transfer, it is possible that the local names and usage of wild fruits unique to an area have been replaced by those from other areas. It also suggests that location information, such as the detailed location of useful natural resources, has become increasingly unavailable for transfer.

Previous studies have suggested that cultural knowledge in adulthood is likely to be mixed information collected from various channels of transfer (Reyes-García et al. 2016). We found that each informant had a maximum of eight channels of knowledge transfer for the use of wild fruits. Also, those born in the period 1990-2009 had a median of one channel of transfer, while older generations had a median of approximately two channels of transfer, although it is not clear in which part of their life the two channels existed and they might not have endured beyond childhood.

\section{Preserving Children's Experiences}

It has been suggested that a decline in or loss of experience of using natural resources may further reduce people's interest in and awareness of biodiversity and its benefits (Soga and Gaston 2016) and that providing environments and opportunities to enhance interactions between humans and nature would restore a connection to nature (Miller 2005). As more efforts for conservation and restoration of biodiversity and ecosystem services are demanded in national and local policies, such activities are expected to increase significantly in the future. Our results showed that the use of wild fruits generally began in childhood, suggesting that these are objects that stimulate children's curiosity and thus may have a role in enhancing their interactions with nature more widely. In order for children to play in nature in their daily lives, they need to have not only an abundance of nature close to their locations but also easy access to it psychologically (Kinoshita 1992). Given the lack of correlation between regional characteristics (urban or rural) and children's experiences of nature (Ye 1994), it is likely that a new mechanism or system is needed to reconnect children with nature, even in rural areas where nature is still abundant.

\section{Conclusion}

Our study results show that the fact that older people tend to have more knowledge about using natural resources compared to younger generations can be attributed to loss of experience and not to age-related accumulation of knowledge (wisdom of the elders). In addition, they revealed that the channels of knowledge transfer had changed significantly in recent years. Information about users and the duration of using knowledge are essential when considering sustaining the transfer of local environmental knowledge. Young people's knowledge of natural resource uses has been declining even in areas with a rich natural environment. As a decline in experience reduces interest in biodiversity and ecosystems, activities to restore connections between people and nature should be encouraged to support conservation efforts into the future.

Supplementary Information The online version contains supplementary material available at https://doi.org/10.1007/s10745-021-00237-w.

Acknowledgements We thank anonymous reviewers and the editor for their constructive comments on the manuscript. Also, many thanks to those who participated in this research in Awaji Island, members of Landscape Plant Resources Department of Graduate School of Landscape Design and Management, University of Hyogo who supported this research, and Chinatsu Zakouji for great assistance. This research was supported by the Environment Research and Technology Development Fund (JPMEERF16S11507) of the Environmental Restoration and Conservation Agency of Japan.

Funding This research was supported by the Environment Research and Technology Development Fund (JPMEERF16S11507) of the Environmental Restoration and Conservation Agency of Japan.

Data Availability The datasets generated and/or analyzed during the current study are available from the corresponding author upon reasonable request.

\section{Declarations}

Informed Consent Informed consent was obtained from all individual informants included in the study.

Conflict of Interest The authors have no conflict of interest to declare.

Open Access This article is licensed under a Creative Commons Attribution 4.0 International License, which permits use, sharing, adaptation, distribution and reproduction in any medium or format, as long as you give appropriate credit to the original author(s) and the source, provide a link to the Creative Commons licence, and indicate if changes were made. The images or other third party material in this article are included in the article's Creative Commons licence, unless indicated otherwise in a credit line to the material. If material is not included in the article's Creative Commons licence and your intended use is not permitted by statutory regulation or exceeds the permitted use, you will need to obtain permission directly from the copyright holder. To view a copy of this licence, visit http://creativecommons.org/licenses/by/4.0/.

\section{References}

Aswani, S., Lemahieu, A., and Sauer, W. H. H. (2018). Global trends of local ecological knowledge and future implications. PLOS ONE 13(4): e0195440. https://doi.org/10.1371/journal.pone.0195440. 
Beck, H. E., Zimmermann, N. E., McVicar, T. R., Vergopolan, N., Berg, A., and Wood, E. F. (2018). Present and future KöppenGeiger climate classification maps at $1-\mathrm{km}$ resolution. Scientific Data 5(1): 180214. https://doi.org/10.1038/sdata.2018.214.

Berkes, F. (1999). Sacred Ecology: Traditional Ecological Knowledge and Resource Management. Taylor \& Francis.

Berkes, F., Colding, J., and Folke, C. (2000). Rediscovery of Traditional Ecological Knowledge as Adaptive Management. Ecological Applications 10(5): 1251-1262. JSTOR. https://doi.org/10. 2307/2641280.

Biodiversity Center of Japan, Ministry of the Environment. (n.d.). Report of Vegetation Survey on 6-7th National Basic Survey on Natural Environment. Retrieved September 23, 2020, from http:// gis.biodic.go.jp/webgis/.

Cavalli-Sforza, L. L., and Feldman, M. W. (1981). Cultural Transmission and Evolution: A Quantitative Approach. Princeton University Press.

Cruz-García, G. S. (2006). The mother - child nexus. Knowledge and valuation of wild food plants in Wayanad, Western Ghats, India. Journal of Ethnobiology and Ethnomedicine 2(1): 39. https://doi. org/10.1186/1746-4269-2-39.

Godoy, R., Reyes-García, V., Broesch, J., Fitzpatrick, I. C., Giovannini, P., Rodríguez, M. R. M., Huanca, T., Leonard, W. R., McDade, T. W., and Tanner, S. (2009). Long-Term (Secular) Change of Ethnobotanical Knowledge of Useful Plants: Separating Cohort and Age Effects. Journal of Anthropological Research 65(1): 51-67. https://doi.org/10.3998/jar.0521004.0065.105.

Gallois, S., Lubbers, M. J., Hewlett, B., and Reyes-García, V. (2018). Social Networks and Knowledge Transmission Strategies among Baka Children, Southeastern Cameroon. Human Nature 29(4): 442-463. https://doi.org/10.1007/s12110-018-9328-0.

Gómez-Baggethun, E., Mingorría, S., Reyes-García, V., Calvet, L., and Montes, C. (2010). Traditional Ecological Knowledge Trends in the Transition to a Market Economy: Empirical Study in the Doñana Natural Areas. Conservation Biology 24(3): 721-729. https://doi.org/10.1111/j.1523-1739.2009.01401.x.

Hanazaki, N., Herbst, D. F., Marques, M. S., and Vandebroek, I. (2013). Evidence of the shifting baseline syndrome in ethnobotanical research. Journal of Ethnobiology and Ethnomedicine 9(1): 75. https://doi.org/10.1186/1746-4269-9-75.

Himiyama Y., (1995). 1.4 Land Use in Japan circa 1950 (pp.8-9), 1.5 Land Use in Japan circa 1985 (pp.10-11), 1.6 Land Use in Japan circa 1900-1985 (pp.12-13), Nishikawa O., Himiyama Y. et al. eds., Atlas - Environmental Change in Modern Japan (in Japanese), Asakura Publishing Co., Ltd.

Ianni, E., Geneletti, D., and Ciolli, M. (2015). Revitalizing Traditional Ecological Knowledge: A Study in an Alpine Rural Community. Environmental Management 56(1): 144-156. https://doi.org/10. 1007/s00267-015-0479-z.

Ichinose, T., and Ito, K. (2007). Comparison of forests in the latter Edo and Showa era in Awaji Island, central Japan. Journal of Rural Planning Association 26(Special_Issue): 203-208. https://doi.org/ 10.2750/arp.26.203.

Japan Meteorological Agency. Sumoto Average yearly rate. Retrieved September 24, 2020, from http://www.data.jma.go.jp/obd/stats/ etrn/view/nml_sfc_ym.php?prec_no $=63 \&$ block_no $=47776 \&$ year $=\&$ month $=\&$ day $=\&$ elm $=$ normal $\&$ view $=$.

Kinoshita, I. (1992). A Study on Children's Contact with Nature in Rural Areas Compared with Urban Areas. Journal of Architecture and Planning 431: 107-118 (in Japanese, English summary). https://doi.org/10.3130/aijax.431.0_107.

Kobayashi, T., Kurosaki, N., and Miyake, S. (2012). Flora of the Awaji Island (revised and enlarged edition). Natural System Institute Hyogo, Japan.
Koster, J., Bruno, O., and Burns, J. L. (2016). Wisdom of the Elders? Ethnobiological Knowledge across the Lifespan. Current Anthropology 57(1): 113-121. https://doi.org/10.1086/684645.

Mattalia, G., Stryamets, N., Pieroni, A., and Sõukand, R. (2020). Knowledge transmission patterns at the border: ethnobotany of Hutsuls living in the Carpathian Mountains of Bukovina (SW Ukraine and NE Romania). Journal of Ethnobiology and Ethnomedicine 16(1): 41. https://doi.org/10.1186/s13002-020-00391-3.

Miller, J. R. (2005). Biodiversity conservation and the extinction of experience. Trends in Ecology \& Evolution 20(8): 430-434. https://doi.org/10.1016/j.tree.2005.05.013.

Ministry of Agriculture, Forestry and Fisheries. (2015). 2015 Census of Agriculture and Forestry. Retrieved March 17, 2020, from https://www.e-stat.go.jp/stat-search/files?page=1\&layout=datal ist \& toukei $=00500209 \&$ tstat $=000001032920 \&$ cycle $=0 \&$ tclass $1=$ $000001077437 \&$ tclass $2=000001077396 \&$ tclass $3=0000010932$ $35 \&$ tclass $4=000001093499$.

Olsson, P., and Folke, C. (2001). Local Ecological Knowledge and Institutional Dynamics for Ecosystem Management: A Study of Lake Racken Watershed, Sweden. Ecosystems 4(2): 85-104. https://doi.org/10.1007/s100210000061.

One, Y., Yamamoto, S., Sawada, Y., Oyabu, T., and Fujihara, M. (2013). Study on children's play and nature experiences in the northern part of Awaji Island. Landscape Planning \& Horticulture 15: 9-14. (in Japanese, English summary).

Pearce, T., Wright, H., Notaina, R., Kudlak, A., Smit, B., Ford, J., and Furgal, C. (2011). Transmission of Environmental Knowledge and Land Skills among Inuit Men in Ulukhaktok, Northwest Territories, Canada. Human Ecology 39(3): 271-288. https://doi.org/10. 1007/s10745-011-9403-1.

Reyes-García, V., Gallois, S., and Demps, K. (2016). A Multistage Learning Model for Cultural Transmission: Evidence from Three Indigenous Societies. In H. Terashima and B. S. Hewlett (Eds.), Social Learning and Innovation in Contemporary Hunter-Gatherers: Evolutionary and Ethnographic Perspectives (pp. 47-60). Springer Japan. https://doi.org/10.1007/978-4-431-55997-9_4.

Reyes-García, V., Luz, A. C., Gueze, M., Paneque-Gálvez, J., Macía, M. J., Orta-Martínez, M., and Pino, J. (2013). Secular trends on traditional ecological knowledge: An analysis of changes in different domains of knowledge among Tsimane' men. Learning and Individual Differences 27: 206-212. https://doi.org/10.1016/j.lindif.2013.01.011.

Senda, M.(1992). Kodomo to Asobi: Kankyo kenchikuka no me [Children and Play: An Environmental Architect's Eye]. Iwanami Shoten, Publishers.

Soga, M., and Gaston, K. J. (2016). Extinction of experience: The loss of human-nature interactions. Frontiers in Ecology and the Environment 14(2): 94-101. https://doi.org/10.1002/fee.1225.

Statistics Bureau of Japan. (2015). 2015 National Census Population Basic Count. Retrieved March 1, 2020, from https://www.e-stat. go.jp/dbview?sid=0003148500.

Sujarwo, W., Arinasa, I. B. K., Salomone, F., Caneva, G., and Fattorini, S. (2014). Cultural Erosion of Balinese Indigenous Knowledge of Food and Nutraceutical Plants. Economic Botany 68(4): 426-437. https://doi.org/10.1007/s12231-014-9288-1.

Tang, R., and Gavin, M. C. (2016). A classification of threats to traditional ecological knowledge and conservation responses. Conservation and Society 14(1): 57. https://doi.org/10.4103/0972-4923. 182799.

Uchida, K., and Kamura, K. (2020). Traditional Ecological Knowledge Maintains Useful Plant Diversity in Semi-natural Grasslands in the Kiso Region, Japan. Environmental Management 65(4): 478-489. https://doi.org/10.1007/s00267-020-01255-y.

von Glasenapp, M., and Thornton, T. F. (2011). Traditional Ecological Knowledge of Swiss Alpine Farmers and their Resilience to 
Socioecological Change. Human Ecology 39(6): 769-781. https:// doi.org/10.1007/s10745-011-9427-6.

Ye, K.-R. (1994). The Relationship Between a Change in Children's Nature Experiences and the Characteristics of Their Residential Areas. Journal of the Japanese Institute of Landscape Architecture 58(5): 245-248 (in Japanese, English summary). https://doi.org/ 10.5632/jila.58.5_245.
Zarger, R. K., and Stepp, J. R. (2004). Persistence of Botanical Knowledge among Tzeltal Maya Children. Current Anthropology 45(3): 413-418. https://doi.org/10.1086/420908.

Publisher's Note Springer Nature remains neutral with regard to jurisdictional claims in published maps and institutional affiliations. 